\title{
Unapologetically faith based: The nature of donor engagement in the context of South African faith-based organisations
}

Author:

Nadine F. Bowers du Toit ${ }^{1}$ (D)

\section{Affiliation:}

${ }^{1}$ Department of Practical Theology and Missiology, Faculty of Theology, Stellenbosch University, Stellenbosch, South Africa

Corresponding author: Nadine F. Bowers du Toit, nbowers@sun.ac.za

\section{Dates:}

Received: 30 Apr. 2019 Accepted: 14 Aug. 2019

Published: 12 Dec. 2019

How to cite this article: Bowers du Toit, N.F., 2019, 'Unapologetically faith based: The nature of donor engagement in the context of South African faith-based organisations', HTS Teologiese Studies/Theological Studies 75(4), a5529. https://doi.org/ 10.4102/hts.v75i4.5529

\section{Copyright:}

(C) 2019. The Authors. Licensee: AOSIS. This work is licensed under the Creative Commons Attribution License.
The funding of faith-based organisations (FBOs) is often complex and at times unsustainable because of many factors that may render the FBO and its valuable work in serving the most marginalised vulnerable to fickle donor funding. Not least amongst such factors are that of the 'faith factor' - namely, the ways in which the religious dimension of an FBO works - which may be seen as too religious for secular donors such as corporates, government and other international funders. While there is a growing body of literature concerning the effects of donor funding on the work of FBOs, there has been no empirical study conducted in South Africa that specifically explores the issue of donor funding and relationships. This article, therefore, seeks to explore the nature of donor funding in South Africa with regard to the FBO sector, its challenges, sustainability and the role of faith identity regarding the relationship between donors and FBOs.

Keywords: Faith-Based organisations; Donor funding; Faith identity; Theology and development; Non-governmental organisations.

\section{Introduction}

Donor funding of the faith-based organisation (FBO) sector remains a burning issue worldwide, with FBOs largely being dependent on such funding for their survival. This is supported by my own experience as a former staff member within a South African Christian FBO as well as my experience as a member of the board of at least two FBOs over the past 10-15 years in a South African context. Although international studies have reflected on this issue, there are nevertheless no comprehensive South African studies that have explored or reported on the complexities, challenges and opportunities faced by FBOs in engaging with donors. The findings explored in this article originate from a larger study entitled, 'Does faith matter?: Exploring the role of faithbased organisations as civil society actors'. ${ }^{1}$ This article focuses on and explores the empirical findings regarding donor funding and donor relationships. These data arise from both qualitative and quantitative data collected from sampled FBOs in the Cape Metropole (Western Cape province, South Africa) $)^{2}$. The article begins by briefly exploring literature with regard to donorFBO relations, followed by the methodology of the study before describing the emerging empirical findings regarding this specific topic in greater detail. Aspects covered in this article include expenditure and donor funding patters, donor stability and relationships, funding challenges and the role of Christian identity in donor relationships.

\section{Faith-based organisations and donor relationships}

Despite the rising enthusiasm for faith-based organisations within the development sector, donor relationships - more especially those of secular donors with FBOs - have often been fraught with tension.

These relationships are of course often rooted in asymmetrical power relations between mostly Northern donors and Southern recipients (Burchardt 2013:1). One of the key emerging trends in this dynamic is the fact that secular donors have often tended to 'build relationships with FBO's that most resemble secular NGO's' and which, therefore, are 'liberal' or 'moderate' faith actors

1.This study was conducted between January 2016 and March 2018 and seeks to explore the current and potential role of faith-based organisations (FBOs) for transformation in South Africa.

2.It should be noted that this article refers exclusively to Christian organisations working at grassroots level in the development sector and does not include congregations, mission organisations, Christian schools or tertiary institutions in its definition of FBO.

Note: Faith-Based Organisations, sub-edited by Nadine Bouwers du Toit (Stellenbosch University), Vhumani Magezi (North-West University) and Elisabet le Roux (Stellenbosch University). 
(Deneulin \& Bano 2009:25; cf. Clarke 2007:2). The latter relates directly to secular donor fears that FBOs will seek to proselytise and some FBOs have, therefore, in response sought to 'tone down' their faith ethos and become similar to secular non-governmental organisations (NGOs) (Occhipinti 2015:333).

Swart and Van der Merwe (2010:86) note this trend within the South African experience too, with particular mention of the state. Indeed, the 'faith factor' not only affects 'the FBOs positionality in relation to the immediate context of engagement, but also how development policy makers and donors engage with its vision' (Tadros 2011:64). On the other hand, it is argued that those FBOs funded largely by individual donors of faith are less likely to experience this issue. Indeed, Berger (2003) notes that:

$[I] \mathrm{n}$ order to maintain organizational independence, most $\mathrm{RNGO}^{3} \mathrm{~s}^{3}$ (FBO's) are privately funded, with a substantial portion of financial resources coming from members in the form of donations, dues or established tithing mechanisms within the religion itself. (p. 29)

The latter - particularly in the form of support from local congregations or individual Christian donors - can be an antidote to challenges such as 'mission and identity drift' because of pressure from secular donors (cf. Moyer, Sinclair \& Spaling 2011:34, 24). Mission and identity drift is exemplified by the FBO minimising or discarding its original Christian identity in order to 'fish' in the secular donor pool, which might have little tolerance for more overtly faith-based work. This need not, however, be true in every case. A Nigerian FBO study, however, notes that despite the inherent faith ethos of their work, 'their external funders and partner organisations seemed to respect their desire to operate in compliance with religious values and injunctions' (Leurs 2012:716).

Other donor issues as noted by international scholars include government control as FBOs are regarded purely as objects of service delivery, equality of partnership between donors and FBOs and the restriction of funding to specific causes, amongst others (Eggers 2008:7; James 2009:18; Moksnes \& Melin 2013).

Donor funding frameworks are also identified as inhibiting the organisation's ability to 'enhance downward accountability' with regard to those they serve. Monitoring and evaluation tools such as 'log frames' (Logical Framework), through which the so-called success of the FBO's programme work is measured, are often based more on value for money for the donor than on measuring the meeting of grassroots needs.

This focus on the donor rather than on the needs of the beneficiary community or FBO also relates to the ways in which donors often support fashionable causes in the short term rather than long-term, really felt needs (Tadros 2011:66). Rasmussen (2013:238) affirms this by stating that donor funding is notoriously 'fickle, as it is usually provided for 3. Religious non-governmental organisations. time-specific projects and donors may withdraw their funding as their priorities change'. This at times leads to vulnerability within FBOs, which may be forced to scale down their operations and services because of withdrawal of funding. Tadros (2011:65) also highlights the frustration of FBOs with donors who only saw them as service delivery agents, rather than as partners in development and catalysts for change.

James (2011:116), therefore, argues that FBOs should have the courage to define clearly what faith means to them and how it operates in their context as the benefit is that it 'will ensure coherence between what an FBO believes (its theology of development) and what it does (its organisational behaviour and programmes)'. This, he argues, is important for any NGO and points out that secular funding is not always positive for FBOs. Dependence particularly on outside donor funding will result in reduced autonomy and accountability to supporters and beneficiaries and 'the tendency to orient their activities to donor preferences rather than their own activities or perceived local needs' (Leurs 2012:717). This had severely negative consequences for a Catholic FBO in Uganda which noted that while donors saw what they did as a programme, they saw it as a ministry (Rasmussen 2013):

[I]n the language of the donors it's a program, but actually it's a ministry, we are his (God's) neck, his hands, his arms, we have to go back to our roots. (p. 239)

\section{Background and methodology Background of the study}

The findings and focus of this study must be understood within the framework of the broader study within which it is positioned, namely, the project entitled, 'Does faith matter? Exploring the role of faith-based organisations as civil society actors $^{\prime 4}$. In recent years, other South African scholarly works have focused more specifically on denominations, broader national ecumenical bodies and FBO case studies (cf. Swart et al. 2010, 2012); however, there remains little systematic study of the nature and contribution of the FBO sector from a multi-disciplinary (and more so theological) perspective. This study sought to focus specifically on Christian FBOs that are based at grassroots level and involved in direct development and social service delivery work in limiting scope. This study's central problem question is, 'what is the current and potential role of faith-based organisations for transformation in South Africa?'. The broader study also has several objectives ${ }^{5}$, one of which includes the objective to 'explore the impact of secular donors on the mission and vision of FBOs and their programmes'. This article, therefore, focuses on this

4.Various findings from the study are presented in this edition. This study was funded by the National Research Foundation of South Africa.

5.Objectives:

- To discuss the positioning of FBOs within South African civil society as social welfare delivery agents

- To investigate the value ascribed to Christian theology, ethics and beliefs in shaping FBO practice

- To explore the impact of secular donors on the mission and vision of FBOs and their programmes

- To explore how partnerships between FBOs and local congregations can result in more holistic congregational praxis

- To discuss the value of FBO interventions in addressing the marginal status of To discuss the value of FBO interventior
women and children within SA society.

- To discuss the gendered nature of development interventions by FBOs. 
objective by, firstly, exploring the nature of funding in general through data on expenditure, sources and weighting of donor funding and reliability of funding, followed by an exploration of the challenges of donor funding, which indeed include the manner in which secular donors may impact the vision and mission of FBOs and their programmes.

\section{Methodology}

This article reports only on the findings pertaining to donor funding within the broader study and uses mixed-methods approach as it includes both qualitative and quantitative methods in order to present a clearer picture of organisations' engagement with donors. The research employed a multimethods or mixed-methods approach in order to garner basic information about the nature and work of FBOs, as well as to explore the manner in which they interpret and understand their positioning within civil society. A mixed-methods approach, therefore, ensures that the conclusions ultimately generated are based on more than one source of evidence, which in turn should assist in increasing the credibility of the research.

As mentioned above, the study focuses on what is termed the Cape Metropole within the Western Cape province of South Africa. The type of FBO we sought for the study was identified according to the following criteria: (1) those who in some way identify as faith based (however what they understood this to mean was left open), (2) are registered as trusts, public benefit organisations, etc., with the South African state and (3) are development-type organisations working at the local level. The sample does not, therefore, include other faith-based entities such as local congregations, traditional mission agencies, etc. For the quantitative part of the study, a survey was designed and electronically sent via Survey Monkey to 80 Christian organisations which fitted the basic criteria of inclusion. These organisations were drawn from several FBO and donor databases. As a mixed-methods study, it therefore includes both data from the survey conducted and thematically coded and analysed findings from in-depth interviews conducted with 10 FBO leaders purposively selected from the 42 FBOs that completed the survey in order to sharpen our understanding of the initial quantitative data. These organisations were purposively sampled from the FBOs responding to the survey in order to report on a range of topics within the FBO typology as provided by Sider and Unrah (2004). It is important to note that one of the criteria was that they should self-identify as an FBO and the selected FBOs could be identified as falling into the following categories: faith permeated, faith centred, faith affiliated and faith background (Sider \& Unrah 2004:112-115).

ATLAS.ti, a qualitative analysis software tool, was used to assist in the thematic coding of the qualitative data arising from the semi-structured interviews. Only codes pertaining to funding or funding and identity were analysed. The quantitative data arising from the survey were used in order to identify aspects such as expenditure, the nature of donors, sources of funding, etc., which were then further interpreted as these interact with the qualitative findings. Ethical clearance was obtained from the Ethics Committee of Stellenbosch University and both the

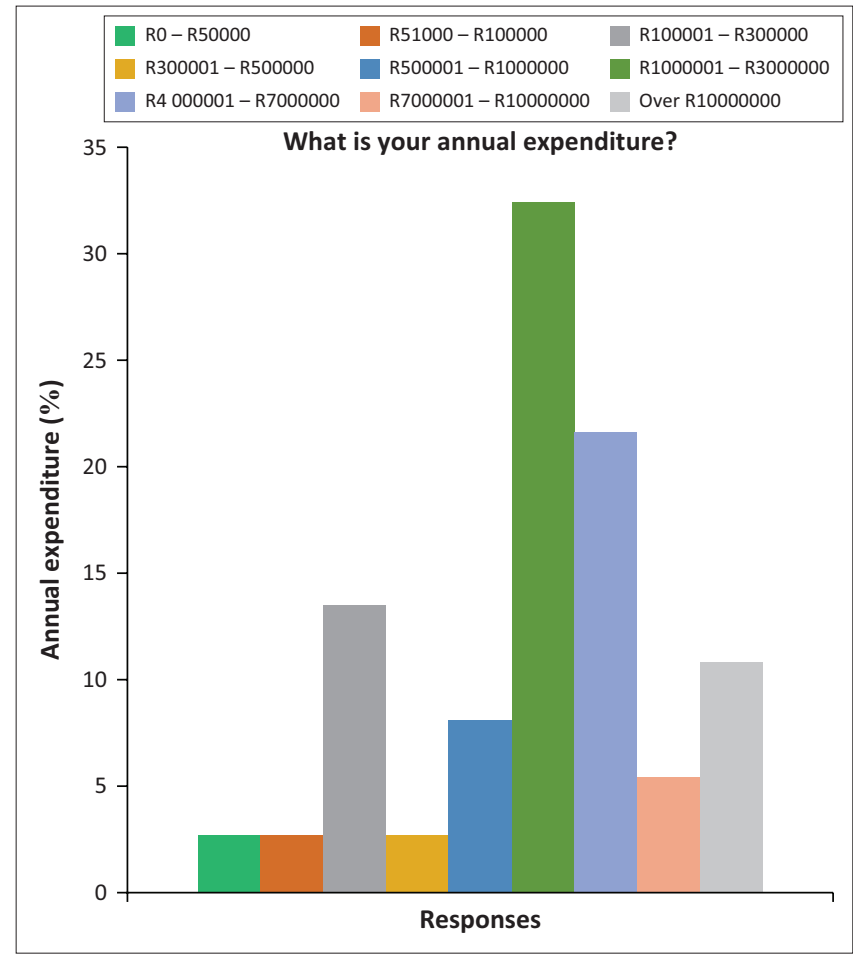

FIGURE 1: Gross annual expenditure of faith-based organisations.

survey data and interviews required separate consent forms. In order to protect participants' anonymity, code names (with letter) were used for the organisations ${ }^{6}$.

\section{Findings}

Several key themes emerged as the interviews were coded, which are discussed in this section, and which reveal the reality of the intersection between funding and the praxis of FBOs within the South African context. This is supported by the findings of the survey conducted with a larger group of FBOs from which the interviewed FBO leaders were drawn.

\section{Annual expenditure}

From Figure 1, it is clear that about one-third (or 30\%) of organisations' budgets fall within the R1 000000 - R3 000000 category, followed by the R4 000000 - R7 000000 category (just over $20 \%$ ). Less than $10 \%$ of FBOs surveyed were below the R1 000000 mark. Of course, it is important to note that this is a full operational budget, which includes organisational overheads, programme costs (both indirect and direct) and salaries.

\section{Sources of donor funding}

Sources of funding range from individuals to corporates, trusts, international donors and government.

The highest percentage appears to be government, followed by individual Christians and then South Africa-based donor organisations and trusts. Own income generation was also surprisingly high. Formal international funding ranked lowest 6.Ethics clearance was obtained via the ethics committee. 




SA, South Africa(n); USAID, United States Agency for International Development; Org, organisation.

FIGURE 2: Responses to the question, 'what sources of funding do you have?'

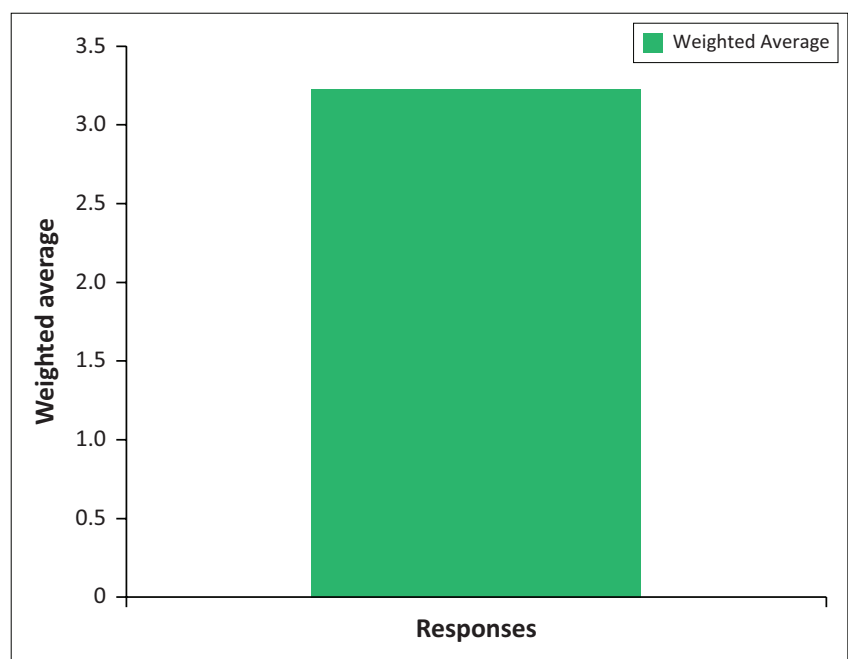

FIGURE 3: Weighted average of responses to the question, 'on a scale of 1 to 5 where 1 is "extremely unstable" and 5 is "always stable", how would you rate the stability of your funding?'

on the list and one could surmise that is because some donors do not recognise South Africa as a low-income country despite high rates of inequality and poverty. The interview analysis revealed that one of the most sustainable sources of donor income for Christian FBOs was individual Christians or families that had been long-term donors (Respondents A and B) - a fact which is supported by the survey data above. It is important to note that organisations that mentioned the sustainability of this kind of income were also founded from a group of churches or a congregation and are, therefore, possibly building on relational capital. From Figure 3, it is clear that the overall stability and reliability of funding is good.

\section{Main funding challenges}

Despite the general reliability and stability of funding as noted above, part of the survey included open- ended questions and one of these questions included a question



FIGURE 4: Responses to the question, 'how strong is the partnership between your organisation and your donors?'

about main funding challenges. Faith-based organisations identified the fact that there was often a lack of fundraising capacity in their organisation which related to both time and skills. This was complicated by the fact that some causes were what they termed 'a hard sell' (e.g. adult homelessness or working with ex-offenders), which implied that they were causes that donors did not easily fund. Faith identity and values were also said to reduce the donor pool, although as the qualitative findings indicate - as well as the relative stability of funding identified in the survey - it is clear that it does not have an overt impact on their sustainability.

Having to fit in with donor requirements and their way of doing things was also noted. A common challenge was that although donors were prepared to fund direct project costs, they did not like to fund salaries and other indirect costs. Finally, many noted a general decrease in donor and donor giving overall - yet reliability of funding is over $60 \%$ stable as shown in Figure 3.

\section{Reasons for loss of funding}

Although the majority of organisations reported fairly strong relationships with their donors as per the survey, several noted the reasons for loss of funding. Probably most common within donor discourse is that of moving away from donor's core funding guidelines. This was noted both in the case of international donors and government departments. Organisations were unapologetic about this, indicating that they need to prioritise their own mission and the nature of their work over and above donor priorities. International donors were also no longer focusing on South Africa (Respondents C and D). With regard to international donors, this has also been linked to donors' fears of political instability and corruption within South Africa (Respondent D). Corporate funders were seen to: ${ }^{7}$

‘[G]enerally pull out of longer-term support because of own financial constraints, or challenges within their own organizations where they have to go, for example, through a process of downscaling and therefore the first thing they cut is the CSI budget.' (Respondent C) 
Donors' shifting priorities were also noted: 'this year we support HIV and the next year we want to support education' (Respondent B). Another organisation mentioned a breakdown in relationship with the donor - largely it appears because of the monitoring and evaluation process (Respondent D). Some have also specifically mentioned that they have lost donors or alienated donors because of their Christian identity. However, as the findings below show, this has not hindered them from continuing to promote their Christian identity (Respondents A and E). This is nuanced as the majority of these organisations claim they do not discriminate against beneficiaries from other faiths or who have no faith affiliation - yet interviews reveal that they are quite open regarding their faith basis both to donors and beneficiaries. Organisations have noted that at times they have had to emphasise the fact that despite the fact that they are unashamedly Christian, they would not discriminate. Some framed their faith integration in their programmes as voluntary (Respondent A) and others incorporated it as ethos. A change in mission and shift in the work of the FBO from a project-based approach towards a training and justice-based approach has also made one organisation vulnerable in particular with individual donors, who could easily identify with the project-based approach that had more visible outcomes.

\section{The role of Christian identity in donor funding}

The majority of organisations noted that no matter how difficult it may be, their basis was their own mission and strategy, and not funding. It is important to note here that the majority of organisations are staffed and have volunteers who self-identify as Christians. These organisations were clear that they would rather not accept donor funding if it was going to steer them away from their strategy. Views such as these emerged:

' $[A]$ nd I think sometimes a challenge where you have to be clear about, your programme cannot be designed by a funder.' (Respondent C)

'If a donor tries to re-direct our focus, we will rather refrain from taking his funding.' (Respondent F)

'We had a few instances where a donor will be very open and say I'm prepared to help you if you denounce that you are Christians, and it was a bit of a discussion within the organization and we decided that we would rather walk away from the donor.' (Respondent E)

'Yes, because we knew and we could see how other, some of the other non-profits that we work with what has happened if they have. It really pushes them and like you are changing your whole strategy and I'm not saying it's not a good idea to change your whole strategy but do you know what you are doing and it's okay if you really have considered this, you know have you thought about it enough ... I think that because the picture and the vision that God gave was quite clear of what we were supposed to do that some people have asked us to start orphanages and to scale what we have and to share what we have and we have to be very clear about saying no to funding.' (Respondent G)

Organisations also specifically noted that even when funded by government departments (such as the
Education Department, Social Development or Prisons Department), they were explicit regarding their faith and this has not necessarily affected these relationships (Respondents A, G, H, C and I). One organisation noted that discarding the historical Christian identity of its organisation to please a funder (in this case they were asked to remove their logo which clearly displayed their Christian identity) was 'like saying this is not my father, this is not my mother. So, we can't do it for anyone else' (Respondent E). It was also interesting to note that one of the organisations that does not specifically identify as an FBO, but which is founded on a Christian ethos and run by Christian staff, noted that even in a meeting with corporate donors they were not afraid to say that 'whilst we are not a faith-based organisation, we are driven by our Christian faith' (Respondent J).

Even in terms of application for funding, some are specific about not applying for funding from donors: whose 'ethos is not in alignment with our ethos we will not even apply' (Respondent F). While this view is not commonly held by all organisations, this organisation was clear that the Lotto Trust and companies that sell alcoholic beverages were not acceptable as they saw donors as partners and such funding violated their faith ethos as they were seen to support gambling and alcoholism. These findings are not surprising when one notes that the majority of organisations have a strong faith identity as a driver, which drives the mission and vision of the organisation.

\section{Sustainability}

The issue of financial sustainability is widely recognised as a risk to FBOs (and NGOs in general). How, then, do FBOs ensure this? It was surprising (or perhaps not as surprising when one notes the strong faith identity of the FBOs interviewed) that quite a few noted faith in God's provision: 'it has been a space of trusting that God will give us enough for today' (Respondent G):

'[S]o operationally, even in funding like massive faith, leaps of faith when it comes to funding to not be anxious about income into the organization which we have witnessed God's miraculous provision many times.' (Respondent F)

Organisations do their own income generation through training or public-private partnerships. This was highlighted, however, as not being able to completely ensure sustainability, which meant that donor funding was still important. It is also interesting to note that the initial sustainability of two of the organisations was seeded and funded by their own spouses' businesses. The latter is of course not sustainable in the long term and they recount how their funding focus has now matured (Respondents $J$ and G). The majority of the organisations emphasised the fact that donor funding is built on relationships. It is clear from the survey results that many organisations are largely funded by individuals and this supports this notion. 
It is also important to note that finding a good donor match - where donors feel that they are investing in something they are passionate about - helps to promote sustainability:

'[A]nd our fundraising is predominantly relational I would say, that even with government and corporate investments, we tend to, you know the process is really one of building relationship with organizations and/or people and/or churches in order to find meaningful and complimentary needs and desires. So, we see it as a process of matching peoples' needs. We have a need and corporates or grant funders or individuals or churches have a need, and we try to match those needs so that we can make sure that if corporate or a church is investing in something, they are investing in something that they feel passionate about. If it's sport, or if it's family preservation or if it's health care or education, that we can find the right pieces to match.' (Respondent C)

One organisation referred to this as 'friend raising':

'So we try to build relationships with people in a meaningful way that they feel like we're not just asking for a cheque, that they are participating in the story.' (Respondent A)

An organisation that based its funding model largely on this, but has shifted its focus away from projects towards training, now has the challenge of convincing people within this relationship that their money is still a good investment and part of the work of God (Respondent B). This was noted as a slow process, but that the donors now understood the vision better and were re-investing. This also points to the fact that donors (particularly trusts and international donors) had to experience accountability from the FBO and be part of the feedback loop for this relationship to continue.

Where donors see giving as 'an act, a once-off act or an act of preference from time to time, depending on their focus, it does create challenges for non-profits' (Respondent C). This makes it clear why most FBOs prefer to see fundraising in terms of 'friend raising' as that solidifies the sustainability of the relationship. Other issues which affect sustainability include issues such as recession and financial trends in the year as well as the rhythm of people's personal finances (Respondents B and C).

\section{Conclusion}

In some ways, the findings of this study with regard to donor relationships is both reflective of the broader international debates and also departs from those findings in significant ways. Faith-based organisations appear to have stable relationships with their donors, which they support through intentional relationship building and ensuring a good 'fit' with their mission. The latter is a particularly interesting finding, as almost all FBOs interviewed noted that their first allegiance was to their mission and not to donor funding. The threat of 'mission drift' because of donor funding appeared to be quite low - at least for the organisations that we interviewed which pertinently emphasised the fact that their faith identity was a non-negotiable one. It is also important to note that that was the case both for organisations which would be identified by Sider and Unrah (2004) as 'faith permeated' and for those that could at best be termed 'faith affiliated' or 'faith background'. Perhaps these findings should not be as surprising within a South African context that claims to have a Christian faith affiliation of over $80 \%$. Key challenges commonly reported include a lack of fundraising capacity, changes in donor priority funding areas and donor's willingness to fund direct project costs, but not the organisational 'machinery' that supports those projects. Overall, the findings show a sector that is relatively financially stable at this point and which, therefore, faces fewer challenges in compromising on its faith ethos.

\section{Acknowledgement}

This article forms part of a National Research Foundation (NRF) Competitive Unrated Grant (CSUR150623120252 9918) project entitled 'Does faith matter?: Exploring the role of faith-based organisations as civil society actors'.

\section{Competing interest}

The author has declared that no competing interest exists.

\section{Author's contributions}

N.F.B.D.T. is the sole author of this research article.

\section{Ethical considerations}

The article followed all ethical standards as stipulated by the University of Stellenbosch and acquired ethical approval from said institution (ethical clearance number: SU-HSD-003625).

\section{Funding information}

This research received funding from the National Research Foundation (NRF) as part of the project entitled 'Does faith matter? Exploring the role of faith-based organisations as civil society actors'.

\section{Data availability statement}

The sharing of raw quantitative data is permissible and should be requested from the project leader; however, data sharing of qualitative data is restricted due to ethical guidelines.

\section{Disclaimer}

The views and opinions expressed in this article are those of the authors and do not necessarily reflect the official policy or position of any affiliated agency of the authors.

\section{References}

Berger, J., 2003, 'Religious nongovernmental organisations: An exploratory analysis', Voluntas 14(1), 15-39. https://doi.org/10.1023/A:1022988804887 
Burchardt, M., 2013, 'Faith based humanitarianism: Organisational change and everyday meanings in South Africa', Sociology of Religion 74(1), 30-55. https:// doi.org/10.1093/socrel/srs068

Clarke, G., 2007, 'Agents of transformation? donors, faith-based organisations and international development', Third World Quarterly 28(1), 77-96.

Deneulin, S. \& Bano, M., 2009, Religion in development: Rewriting the secular script Zed, New York, NY.

Eggers, B.J., 2008, 'The impact of accepting government funds on a faith-based organization: A case study of the Northwest leadership foundation', thesis at the University of Puget Sound, viewed n.d., from http://soundideas.pugetsound.edu/ economicstheses/61.

James, R., 2009, What is distinctive about FBOs? How European FBOs define and operationalise their faith, Praxis paper 22, INTRAC, s.I.

James, R., 2011, 'Handle with care: enaging with faith-based organisations in development in practice', 21(1), 109-117.

Leurs, R., 2012, 'Are faith-based organisations distinctive? Comparing religious and secular NGOs in Nigeria', Development in Practice 22(5-6), 704-720. https://doi. org/10.1080/09614524.2012.685868

Moksnes, H. \& Melin, M., 2013, Report: Faith in civil society religious actors as drivers of change, Uppsala Centre for Sustainable Development, Uppsala University, Uppsala.
Moyer, J.M., Sinclair, J.A. \& Spaling, H., 2011, 'Working for God and sustainability: The activities of faith-based organizations in Kenya', Voluntas December, 1-34.

Occhipinti, L., 2015, 'Faith-based organisations and development', in E. Tomalin (ed.) The Routledge handbook of religions and global development, pp. 331-345, Routledge, New York, NY.

Rasmussen, L.M., 2013, “'To donors it's a program, but to us it's a ministry": The effects of donor funding on a community-based Catholic HIV/AIDS initiative in Kampala', Canadian Journal of African Studies 47(2), 227-247. https://doi.org/10.1080/00083 968.2013 .829952

Sider, R. \& Unrah, H., 2004, 'Typology of religious characteristics of social service and educational organizations and programs', Non-Profit Voluntary Sector Quarterly 33(1), 109-134. https://doi.org/10.1177/0899764003257494

Swart, I. \& Van der Merwe, W., 2010, 'Towards conceptualising faith-based organisations in the context of social welfare and development in South Africa,' in I. Swart, H. Rocher, S. Green \& J. Erasmus (eds.), Religion and Social Development in Post-apartheid South Africa: Perspectives for critical engagement, pp. 75-90, Sun Media, Stellenbosch.

Swart, I., H. Rocher, S. Green \& J. Erasmus (eds.) 2010, Religion and Social Development in Post apartheid South Africa: constructing a North-South dialogue, Sun Media, Stellenbosch.

Tadros, M., 2011, 'The faith factor in reimagining development', IDS Bulletin 42(5), 63-67. https://doi.org/10.1111/j.1759-5436.2011.00253.x 